\title{
10-Point Importance Scale
}

National Cancer Institute

\section{Source}

National Cancer Institute. 10-Point Importance Scale. NCI Thesaurus. Code C153596.

A scale for the subjective scoring of importance that ranges from 0: Not at all important to 10: Extremely important. 